\title{
Mathematical Approach in Rheological Characterizing of Asphalt Emulsion Residues
}

\author{
Seong Hwan Cho ${ }^{1}$ and Jeong Hyuk $\mathrm{Im}^{2}$ \\ ${ }^{1}$ Department of Civil, Construction, and Environmental Engineering, North Carolina State University, Campus Box 7908, \\ 2501 Stinson Drive, Raleigh, NC 27695, USA \\ ${ }^{2}$ Highway Pavement Research Division, Korea Institute of Civil Engineering and Building Technology (KICT), \\ Daehwa-Dong 283, Goyangdae-ro, Ilsanseo-gu, Goyang-si, Gyeonggi-do 411-712, Republic of Korea
}

Correspondence should be addressed to Jeong Hyuk Im; jhim5572@gmail.com

Received 3 October 2014; Accepted 24 December 2014

Academic Editor: Woo-Young Jung

Copyright (C) 2015 S. H. Cho and J. H. Im. This is an open access article distributed under the Creative Commons Attribution License, which permits unrestricted use, distribution, and reproduction in any medium, provided the original work is properly cited.

\begin{abstract}
Three different emulsion residues, such as SS1HP, HFE90, and SS-1VH (trackless), and a base asphalt binder (PG 64-22) are compared to characterize rheological properties by using DSR test. In order to capture the emulsion properties, different frequencies (from 1 to $100 \mathrm{rad} / \mathrm{sec}$ at a $10 \%$ constant shear rate) and temperatures (from $-45^{\circ} \mathrm{C}$ to $75^{\circ} \mathrm{C}$ with $15^{\circ} \mathrm{C}$ increments) were applied. Then, a master curve for shear modulus was plotted for each emulsion. The transition of the HFE90 emulsion from viscous to elastic behavior occurs at lower temperatures, compared to the other materials. This emulsion is known for performing in a wider temperature range as shown in the results. The trackless emulsion presents an elastic behavior at intermediate temperatures. This product is known as having very fast setting and high resistance to shear stresses. The trackless emulsion presents the highest viscous and elastic modulus, followed by the PG 64-22 binder, SS1HP, and HFE90 emulsion. Shear strength test results show a behavior between trackless emulsion and SS1HP similar to the frequency sweep test results performed by DSR.
\end{abstract}

\section{Introduction}

As the need for new construction for asphalt pavement has been decreased over time, an increased interest in preventive maintenance and rehabilitation has come to the fore. The asphalt emulsion is one of the most effective materials for the preventive maintenance of asphalt pavement. Also, the asphalt emulsion is an ecofriendly material because its construction system does not include heating equipment. For example, chip seals, which are among the most efficient and cost-effective methods utilized by state highway agencies to preserve and rejuvenate existing pavements, are constructed by application of asphalt emulsion and aggregate. The asphalt emulsion is applied as a liquid condition, and then it becomes a residue condition by curing procedure. Therefore, the properties of asphalt residue play a vital role in the performance.

Diverse laboratory tests are usually performed on the asphalt emulsions and their residue. In order to obtain appropriate properties that can be related to field performance, it is critical to obtain an emulsion residue that is representative of the emulsion used in the field.

Takamura [1] proved that high temperatures of distillation procedure, which are $177^{\circ} \mathrm{C}$ or $260^{\circ} \mathrm{C}$, can significantly alter or damage the microscopic structure of the emulsion and thus the residues recovered by these processes do not represent the field conditions where construction is done in ambient temperatures. Also, he proposed a new residue recovery procedure that uses airflow under ambient temperatures to simulate field conditions. The forced airdrying procedure, in which the emulsion was dried under ambient temperatures for 5-6 hours, was found to preserve the microscopic polymer network in the residue.

King et al. [2] showed some early indications about the performance of emulsions made using polymer-modified asphalts. The tests were limited to HF emulsions and a CRS emulsion for both neat and polymer-modified asphalts. 


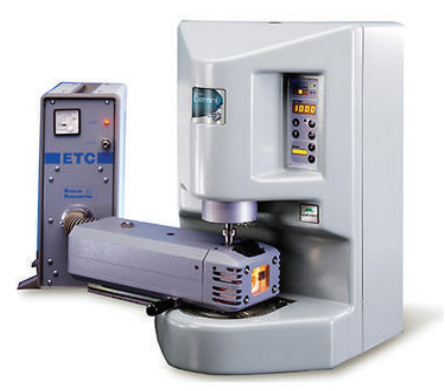

(a)

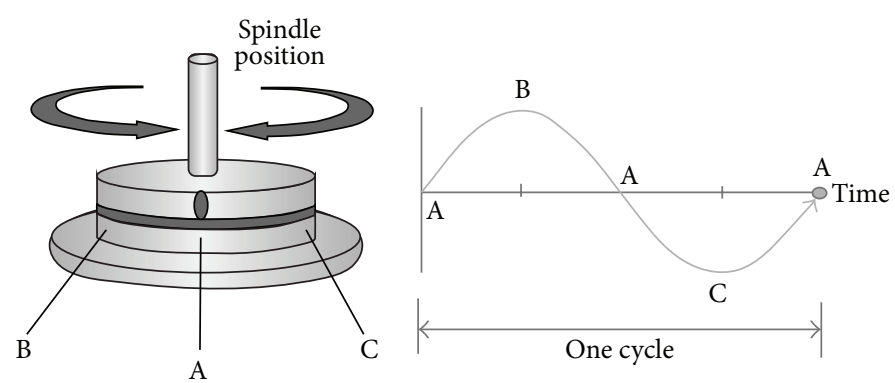

(b)

FIGURE 1: (a) DSR equipment and (b) schematic of cylindrical specimen.

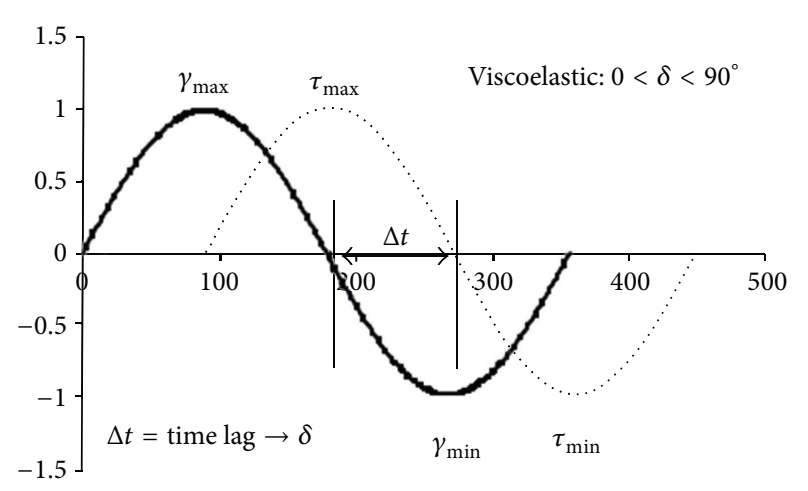

Figure 2: Definition of phase angle.

The asphalts were recovered from the respective emulsions by distillation at $204^{\circ} \mathrm{C}$. It was found that the use of polymermodified binder with an HF (high float) emulsifier could decrease the limiting stiffness temperature by $3^{\circ} \mathrm{C}$.

Also, Barcena et al. [3] proposed asphalt emulsion used for surface treatments from an extension of King's study. This surface performance grading system follows the PG system with certain changes in the dynamic shear rheometer (DSR) high temperature test and the bending beam rheometer (BBR) test specification limits. They proposed that emulsion residues could be efficiently obtained without degrading polymer morphology by a stirred-can procedure performed under a nitrogen blanket at $163^{\circ} \mathrm{C}$ for 170 minutes. A survey by TxDOT found that aggregate loss due to flow and brittle fracture at high and low temperatures, respectively, were the principle modes of distress for surface treatments.

Deneuvillers and Samanos [4] conducted a series of emulsions with different particle size diameters and correlated the various rheological properties like viscosity, breaking index, and cohesion build-up with respect to parameters like median diameter of the emulsion gel particles and their standard deviation and also arrived at characterizing grading curves.

Bec et al. [5] studied an accelerated curing mechanism for cold mixes in laboratory conditions, with the idea of being able to predict final mechanical properties. The study indicates that conditioning of the test pieces at $50^{\circ} \mathrm{C}$ and $10 \%$ $\mathrm{RH}$ gives the same level of resistance after five days that would be obtained in 30 days for test pieces conditioned at $18^{\circ} \mathrm{C}$ and $50 \% \mathrm{RH}$. The results also show that, regardless of the temperature and $\mathrm{RH}$ conditions, it is almost impossible to completely eliminate the water.

\section{Objective}

The objective of this study is to characterize rheological properties of three different asphalt emulsion residues and a base binder by using DSR. The results also will be related to the emulsions performance as a tack coat material.

\section{Methodology}

Three different emulsions SS1HP, HFE90, and SS-1VH (trackless) are used in this study. For the sake of time, the RTFO method has been selected to recover emulsion residues. In addition, a base binder with PG 64-22 is also tested. The samples are characterized by using dynamic shear rheometer (DSR) to find their rheological properties such as shear modulus $\left(G^{*}\right)$ and phase angle $(\delta)$. The proposed test procedure is to run a frequency sweep test from 1 to $100 \mathrm{rad} / \mathrm{sec}$ at a $10 \%$ constant shear rate. The test is conducted at a temperature range of $-45^{\circ} \mathrm{C}$ to $75^{\circ} \mathrm{C}$ with $15^{\circ} \mathrm{C}$ increments (9 temperatures in total) to capture the emulsion properties through its glassy behavior to viscous behavior. Then, a master curve for shear modulus is plotted for each emulsion.

3.1. Dynamic Shear Rheometer Test. The dynamic shear rheometer (DSR) is a common device to characterize the elastic and viscoelastic behaviors of asphalt binders as well as asphalt emulsions at high and intermediate temperature. Figure 1(a) presents the DSR equipment used in this study.

The emulsion residues are obtained using the Superpave binder test procedures by Marasteanu and Clyne [6]. For 


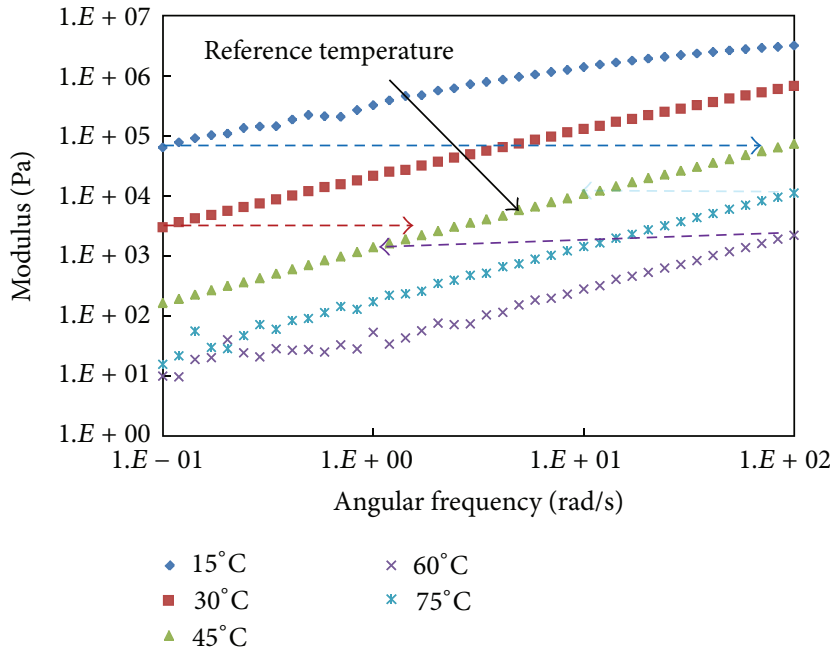

(a)

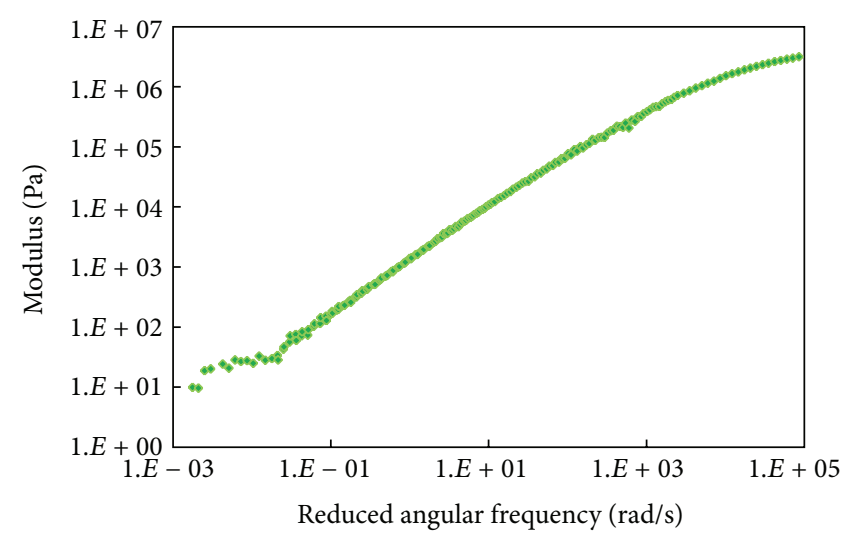

(b)

FIgURE 3: (a) Original frequency sweep data at multiple temperatures and (b) shifted frequency data to a reference temperature.

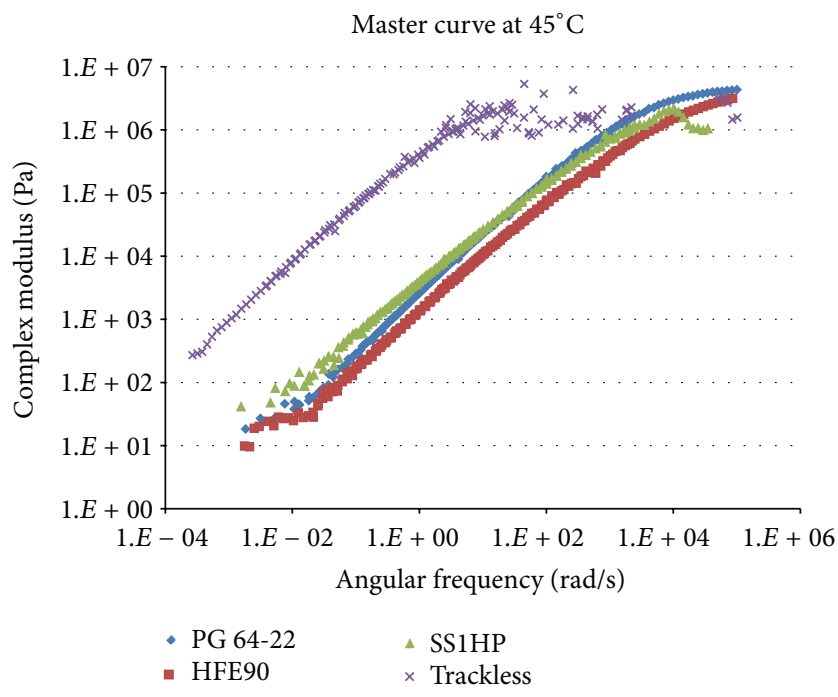

(a)

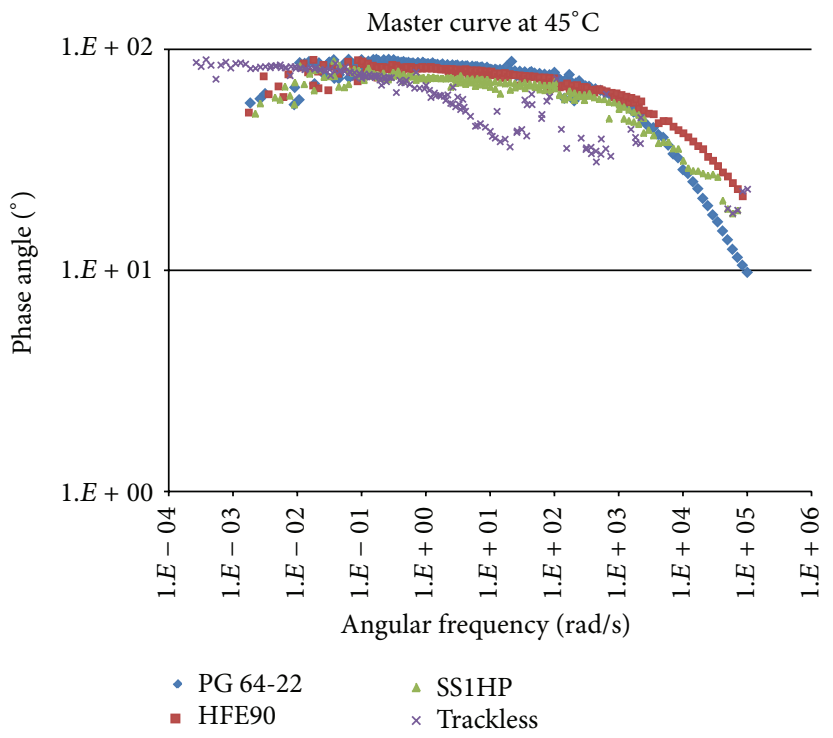

(b)

Figure 4: (a) $G^{*}$ master curve and (b) phase angle results at $45^{\circ} \mathrm{C}$.

the air cured and RTFOT cured specimens tests are performed on the small plate $(8 \mathrm{~mm})$ at intermediate temperatures from $10^{\circ} \mathrm{C}$ to $40^{\circ} \mathrm{C}$ and on the large plate $(25 \mathrm{~mm})$ at high temperatures from $40^{\circ} \mathrm{C}$ to $64^{\circ} \mathrm{C}$. The specimens are $1 \mathrm{~mm}$ thick for the large plate and $2 \mathrm{~mm}$ thick for the small plate. Frequency sweeps are performed from 1 to $100 \mathrm{rad} / \mathrm{sec}$.

This test system consists of parallel metal plates, an environmental chamber, a loading device, and a control and data acquisition and measures the rheological properties of asphalt binder. The test is performed by sandwiching the binder specimen between a fixed plate and a rotated plate on which the torque is applied. The DSR is able to directly apply and measure torque $(T)$ and deflection angle $(\varphi)$. Shear stresses $(\tau)$ and shear strains $(\gamma)$ are calculated and reported by the instrument using the following equations:

$$
\begin{gathered}
\gamma_{\text {max }}=\frac{\varphi \cdot r}{h}, \\
\tau_{\text {max }}=\frac{2 \cdot T}{\pi \cdot r^{3}},
\end{gathered}
$$

where $r$ is sample radius and $h$ is sample height.

Note that the shear stress and shear strain are not uniform in DSR testing. Rather, stress and strain are maximum at the sample periphery and zero at the sample center. The maximum stress and strain at the edge of the sample are 


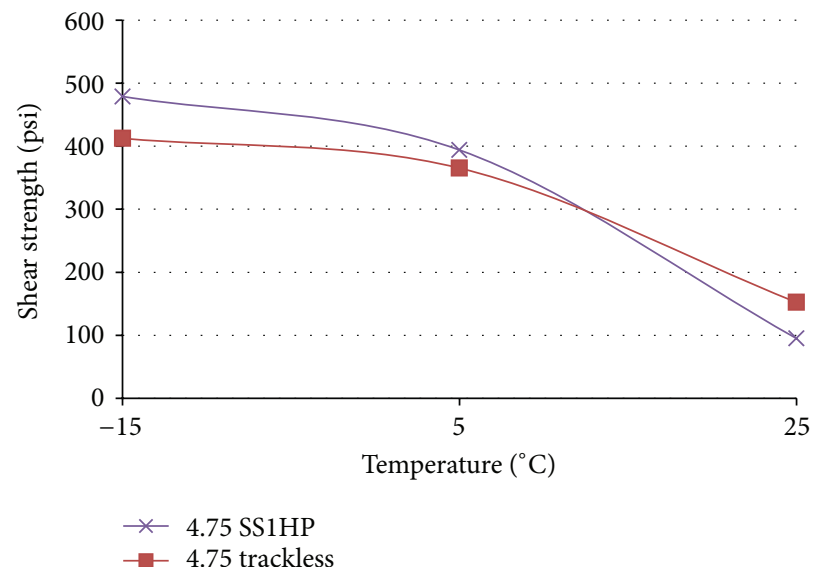

(a)

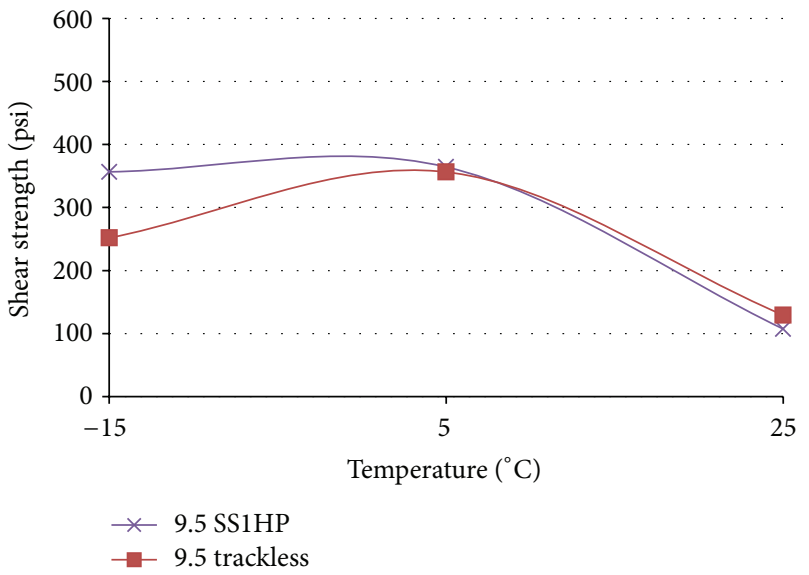

(b)

FIGURE 5: Tack coat shear test results.

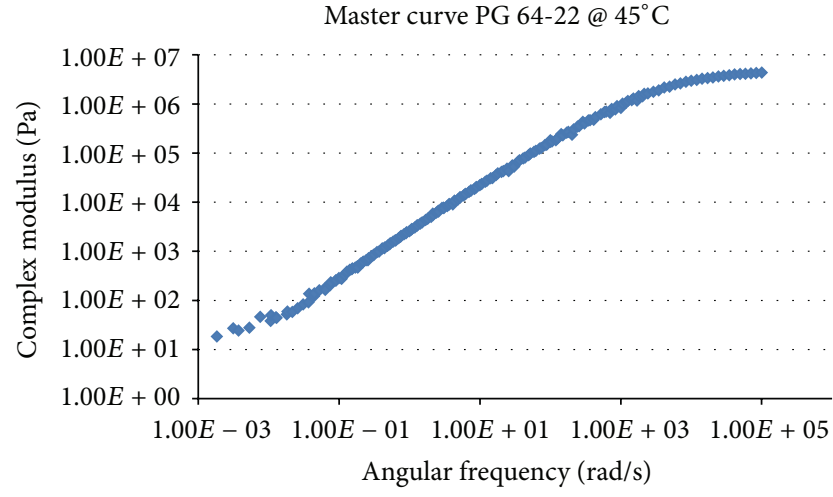

(a)

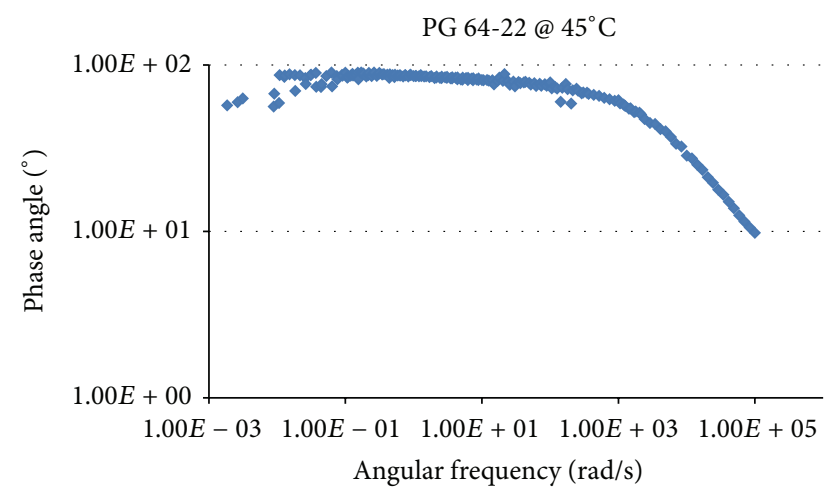

(c)

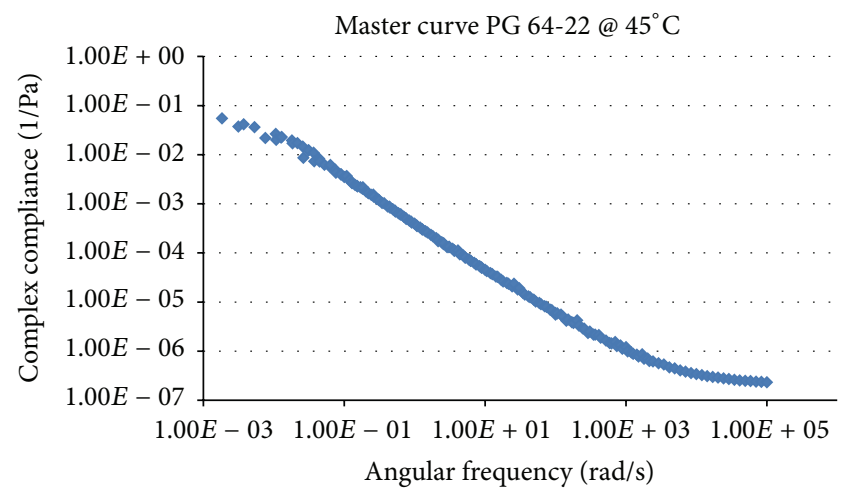

(b)

Complex modulus@each temperature PG 64-22

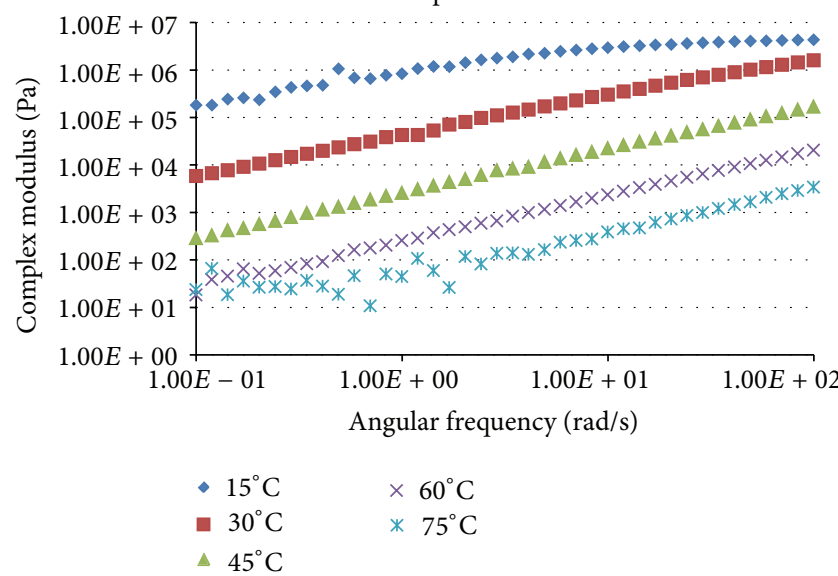

(d)

Figure 6: (a) Complex modulus, (b) complex compliance master curves, (c) phase angle at $45^{\circ} \mathrm{C}$, and (d) complex modulus at each temperature. 


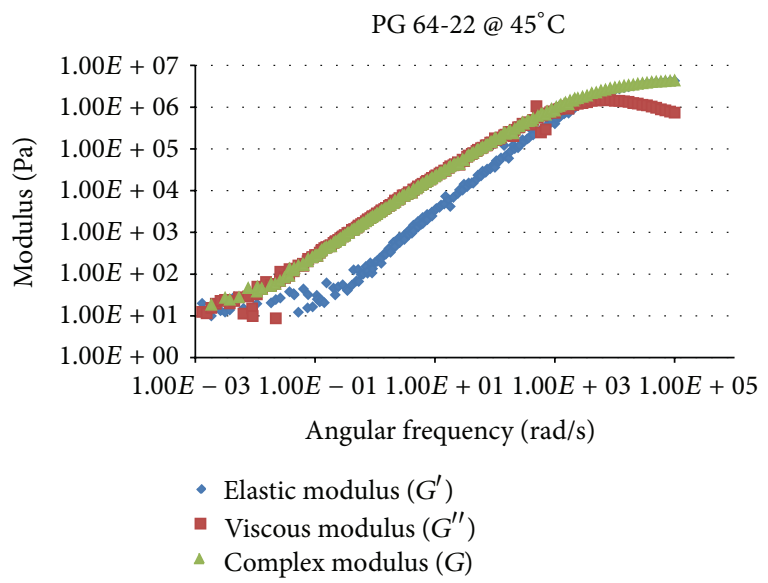

(a)

\begin{tabular}{|c|c|c|}
\hline \multicolumn{3}{|c|}{ Shift factors for PG 64-22 @ $45^{\circ} \mathrm{C}$} \\
\hline $\begin{array}{c}\text { Temperature } \\
\left({ }^{\circ} \mathrm{C}\right)\end{array}$ & \multicolumn{2}{|c|}{$\log a_{T}$} \\
\hline 15 & \multicolumn{2}{|c|}{6.912} \\
\hline 30 & \multicolumn{2}{|c|}{3.07} \\
\hline 45 & \multicolumn{2}{|c|}{0} \\
\hline 60 & \multicolumn{2}{|c|}{-2.4141} \\
\hline 75 & \multicolumn{2}{|c|}{-4.344} \\
\hline \multirow[b]{2}{*}{ WLF } & $\mathrm{C} 1$ & $\mathrm{C} 2$ \\
\hline & 23.633 & 132.23 \\
\hline Arrhenius & \multicolumn{2}{|c|}{ B1 } \\
\hline Кก111 & & \\
\hline
\end{tabular}

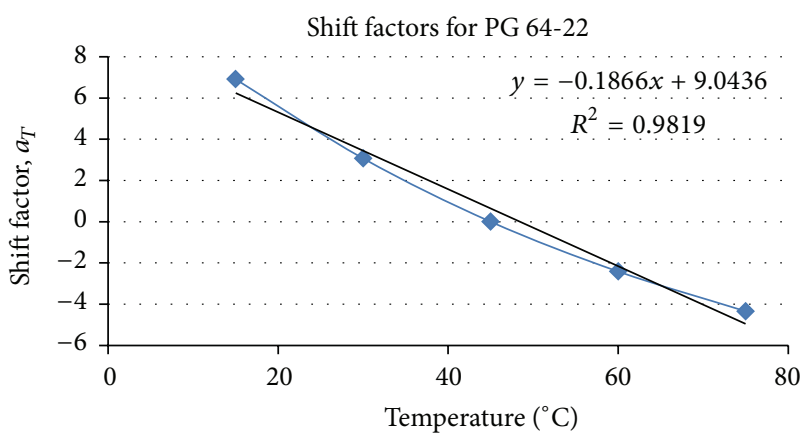

(b)

Figure 7: (a) Elastic and viscous modulus at $45^{\circ} \mathrm{C}$ and (b) shift factors at reference temperature $\left(45^{\circ} \mathrm{C}\right)$.

normally reported in DSR testing, assuming a fixed sample radius and height.

Two important parameters are obtained from the dynamic shear rheometer test on asphalt: $\left|G^{*}\right|$ the complex modulus and $\delta$ the phase angle. These parameters can be used to characterize both viscous and elastic behavior of the material. The complex modulus can be defined as a ratio between the maximum and minimum strain and stress as shown in Figure 2 and (2), respectively:

$$
G^{*}=\frac{\tau_{\max }-\tau_{\min }}{\gamma_{\max }-\gamma_{\min }}
$$

The complex modulus is a measurement of a binder's total resistance to deformation and can be divided into two components, such as a real part and imaginary part. The simple relation is shown below:

$$
\begin{aligned}
G^{*}(\omega) & =G^{\prime}(\omega)+i G^{\prime \prime}(\omega), \\
\left|G^{*}(\omega)\right| & =\sqrt{G^{\prime}(\omega)^{2}+G^{\prime \prime}(\omega)^{2},} \\
G^{\prime}(\omega) & =G^{*}(\omega) \cos (\delta(\omega)), \\
G^{\prime \prime}(\omega) & =G^{*}(\omega) \sin (\delta(\omega)),
\end{aligned}
$$

where $G^{*}(\omega)$ is complex shear modulus at frequency $\omega, G^{\prime \prime}(\omega)$ is dynamic storage modulus at frequency $\omega, G^{\prime}(\omega)$ is dynamic loss modulus at frequency $\omega, \delta(\omega)$ is phase angle at frequency $\omega$, and $i$ is complex number (equal to $\sqrt{-1}$ ).

Additionally, the phase angle can be represented by the following equation:

$$
\delta=\tan ^{-1}\left(\frac{G^{\prime \prime}(\omega)}{G^{\prime}(\omega)}\right) .
$$

The shape of the load, which is used in this test, is sinusoidal, and the loading is controlled by two types, such as constant stress and constant strain mode. The complex shear modulus and phase angle are automatically calculated by proprietary computer software. The more detailed procedures for DSR test can be found in ASTM D7175-05 [7].

Marasteanu and Clyne [6] utilized dynamic shear rheometer (DSR) data to construct master curves for each ofthe residues. Tests were performed at $6^{\circ} \mathrm{C}$ temperature increments from $10^{\circ} \mathrm{C}$ to $64^{\circ} \mathrm{C}$ usingfrequency sweeps from 1 to 100 radians/sec. The master curves were constructed by fitting the Christensen-Anderson-Marasteanu (CAM) model to the $\left|G^{*}\right|$ data obtained with the DSR.

Salomon and Zhai [8] conducted dynamic shear rheometer (DSR) test to evaluate the rheological properties of several types of emulsified asphalts. In their study, rheological 


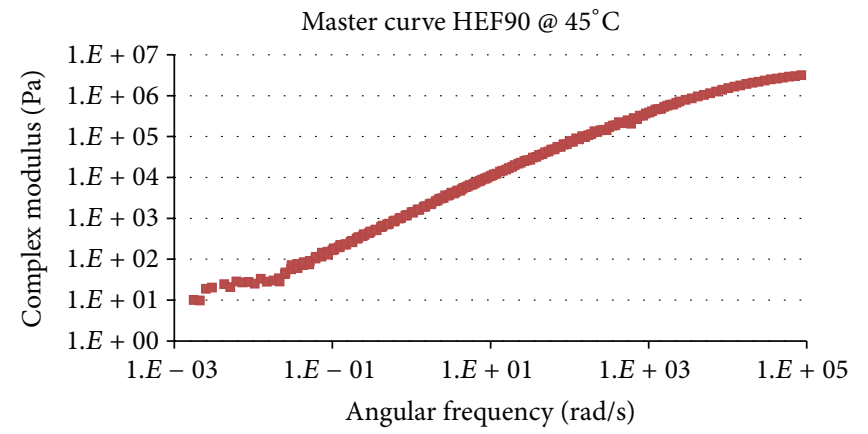

(a)

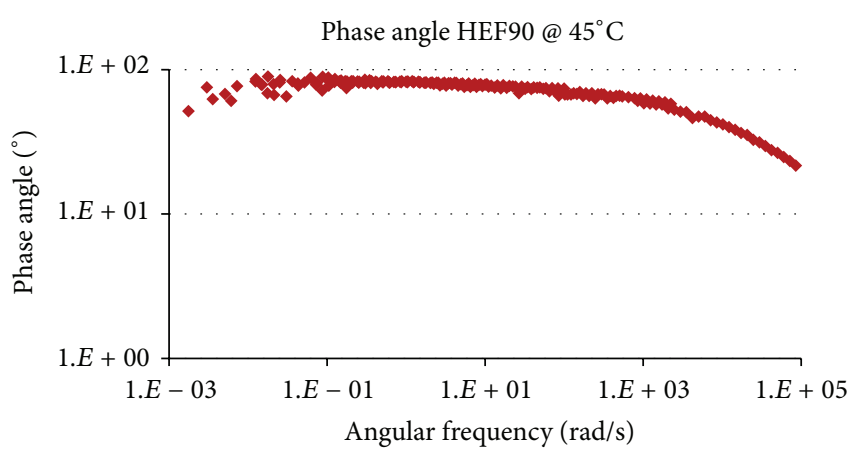

(c)

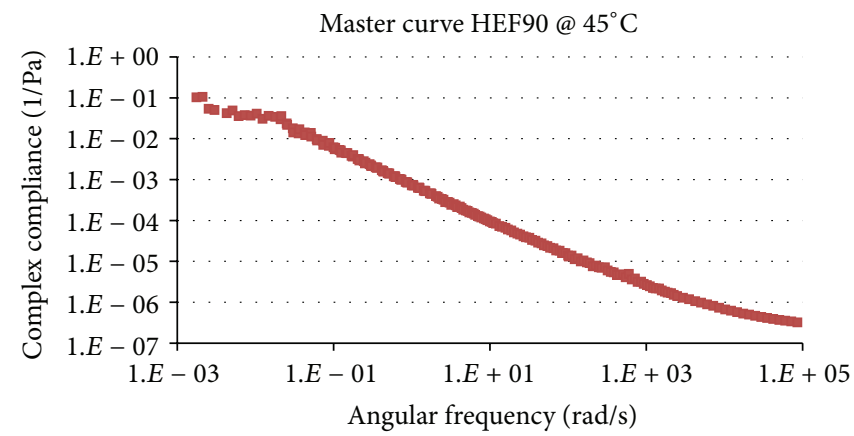

(b)

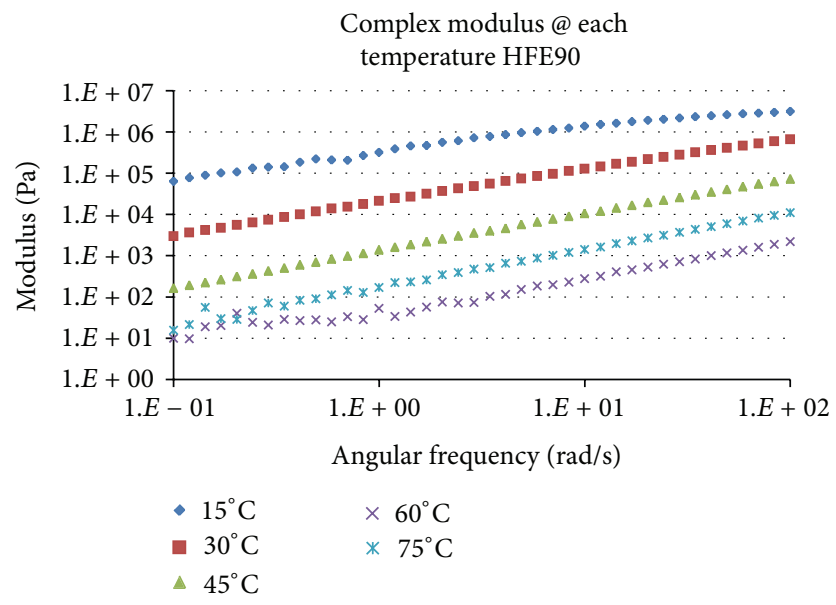

(d)

Figure 8: (a) Complex modulus, (b) complex compliance master curves, (c) phase angle at $45^{\circ} \mathrm{C}$, and (d) complex modulus at each temperature.

properties were obtained by testing emulsified asphalts with test protocols developed for asphalt testing, such as stress sweep, frequency sweep, creep, and recovery. The results demonstrated that rheological measurements can be used to predict the field applications of emulsified asphalts.

Zhai et al. [9] developed several new tests to simulate application conditions of emulsified asphalts by using Bohlin CVO DSR with controlled stress mode. Stress sweeps, time sweep, and temperature sweep tests were all conducted on this DSR. A three-step (low shear rate, high shear rate, and low shear rate) test was developed to simulate spraying and setting characteristics for different emulsions. In this study, they concluded gel point determined by temperature sweep test can be used to study storage stability and setting time for different emulsions and spraying of an emulsion can be simulated using a high shear rate test.

3.2. Time-Temperature Superposition (TTS). Asphalt binder is well-known for thermorheologically simple (TRS) material by most researchers in asphalt pavement field if it is constrained to the so-called linear viscoelastic range. The timetemperature superposition principle $(t$-TS) is a renowned characteristic of thermorheologically simple (TRS) materials. Viscoelastic properties (i.e., the complex modulus $\left|\left(G^{*}\right)\right|$ values and time-temperature $(t-T)$ shift factors) obtained in the linear viscoelastic range at different loading rates and temperatures can be superposed to develop a single master curve by shifting them horizontally to a certain reference temperature. The horizontal distance necessary to superpose a curve to a reference curve, in order to develop a continuous curve, is termed the time-temperature shift factor $\left(a_{T}\right)$, and it is unique to a given temperature.

The effects of time and temperature on viscoelastic material behavior can be combined into a single parameter, called reduced time, through the time-temperature superposition principle. Equation (5) represents a definition of reduced time $(\xi)$ in common form. In terms of frequency domain, the reduced frequency is computed using (6):

$$
\begin{gathered}
\xi=\frac{t}{a_{T}}, \\
f_{R}=f \times a_{T}, \\
\log \left(a_{T}\right)=\alpha_{1} T^{2}+\alpha_{2} T+\alpha_{3},
\end{gathered}
$$

where $f$ is frequency in $\mathrm{Hz}, a_{T}$ is the time-temperature shift factor, $\alpha_{1}, \alpha_{2}, \alpha_{3}$ are coefficients, and $T$ is temperature.

The principle of time-temperature superposition states that the change in a material property (e.g., $\left.\left|G^{*}\right|\right)$ with respect 


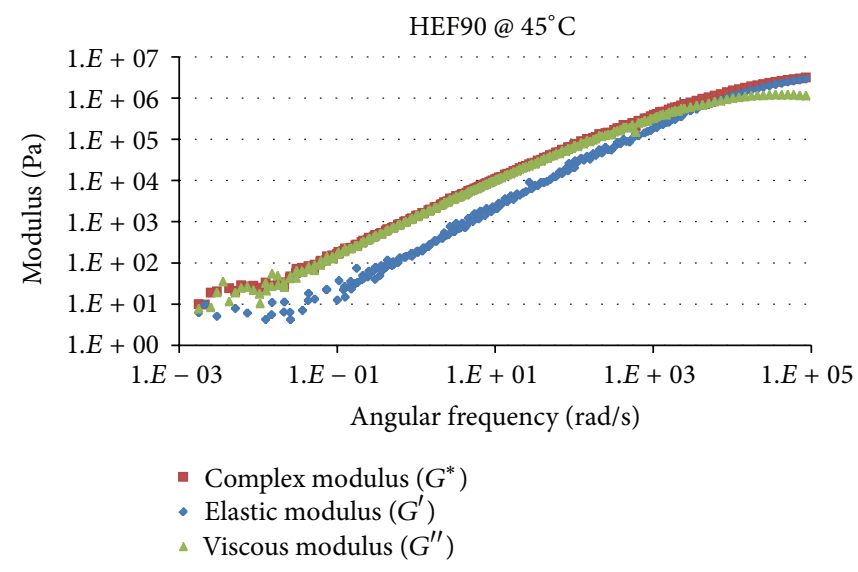

(a)

\begin{tabular}{|c|c|c|}
\hline \multicolumn{3}{|c|}{ Shift factors for HFE90 } \\
\hline $\begin{array}{c}\text { Temperature } \\
\left({ }^{\circ} \mathrm{C}\right)\end{array}$ & \multicolumn{2}{|c|}{$\log a_{T}$} \\
\hline 15 & \multicolumn{2}{|c|}{6.756} \\
\hline 30 & \multicolumn{2}{|c|}{3.117} \\
\hline 45 & \multicolumn{2}{|c|}{0} \\
\hline 60 & \multirow{2}{*}{\multicolumn{2}{|c|}{$\begin{array}{l}-2.2463 \\
-4.0324\end{array}$}} \\
\hline 75 & & \\
\hline \multirow[b]{2}{*}{ WLF } & $\mathrm{C} 1$ & C2 \\
\hline & 19.992 & 117.9 \\
\hline Arrhenius & \multicolumn{2}{|c|}{$\begin{array}{c}\text { B1 } \\
49813\end{array}$} \\
\hline
\end{tabular}

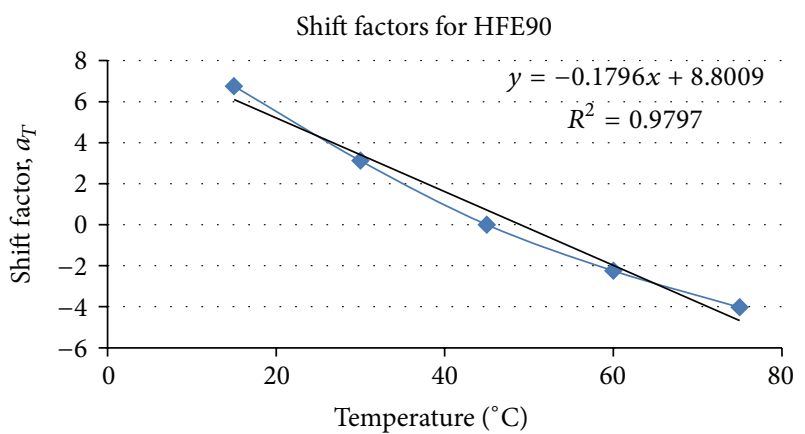

(b)

FIgURE 9: (a) Elastic and viscous modulus at $45^{\circ} \mathrm{C}$ and (b) shift factors at reference temperature $\left(45^{\circ} \mathrm{C}\right)$.

to temperature is equivalent to a horizontal shift on the log time or log frequency scale [10]. This principle implies that increasing temperature is equivalent to increasing loading time (or decreasing loading frequency). Similarly, decreasing temperature is equivalent to decreasing loading time (or increasing loading frequency).

The data at various temperatures are shifted with respect to time until the curves merge into a single smooth function. This behavior allows for the horizontal shifting of the data onto an arbitrarily selected reference temperature curve to form a single curve, the master curve, which is used to describe the constitutive behavior of asphalt binder over a wide range of temperatures and frequencies. The concept of a master curve is illustrated in Figure 3.

3.3. Shift Factor Laws. The $t$-T shift factor $\left(a_{T}\right)$ is the amount of horizontal shift in log scale that is required to create the continuous curve. The amount of shifting is dependent on the temperature chosen as the reference temperature and, therefore, varies by temperature. The amount of shifting along the horizontal $x$-axis in a typical time-temperature superposition (TTS) plot required to align the individual experimental data points into the master curve is generally described using one of two common theoretical models. The first of these models is the Williams-Landel-Ferry (WLF) equation. The Williams-Landel-Ferry equation can be used to determine the time-temperature shift factors at any temperature for a given reference temperature by the following equation:

$$
\log \left(a_{T}\right)=\frac{-C_{1}\left(T-T_{0}\right)}{C_{2}+\left(T-T_{0}\right)},
$$

where $C_{1}$ and $C_{2}$ are constant, $T_{0}$ is reference temperature (in $K$ ), $T$ is measurement temperature (in $K$ ), and $a_{T}$ is shift factor.

The WLF equation is typically used to describe the timetemperature behavior of polymers in the glass transition region. The equation is based on the assumption that, above the glass transition temperature, the fractional free volume increases linearly with respect to temperature. The model also assumes that as the free volume of the material increases, its viscosity rapidly decreases.

The other model commonly used is the Arrhenius equation (9). The Arrhenius equation is typically used to describe behavior outside the glass transition region but has also been used to obtain the activation energy associated with the glass transition:

$$
\log \left(a_{T}\right)=C\left(\frac{1}{T}-\frac{1}{T_{0}}\right)=\frac{0.4347 B_{1}}{R}\left(\frac{1}{T}-\frac{1}{T_{0}}\right),
$$

where $C$ is constant, $B_{1}$ is activation energy $(\mathrm{J} / \mathrm{mol})$ associated with the relaxation, $R$ is ideal gas constant $(8.314 \mathrm{~J} / \mathrm{mol}), T$ is 


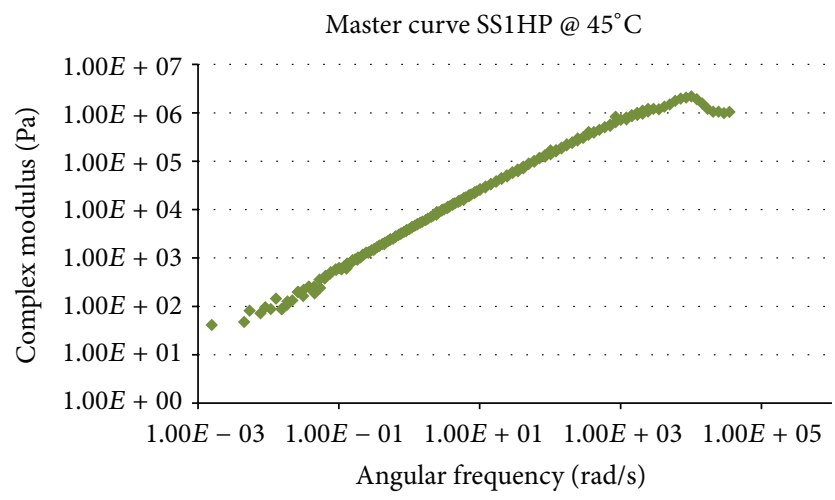

(a)

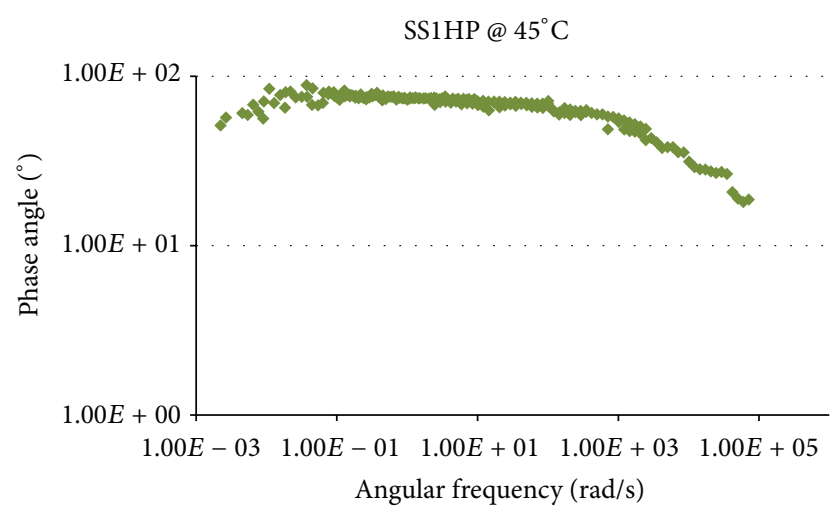

(c)

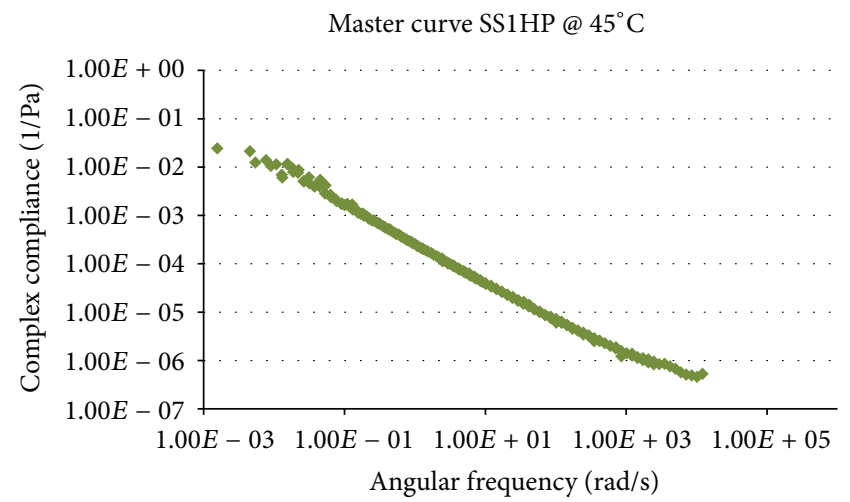

(b)

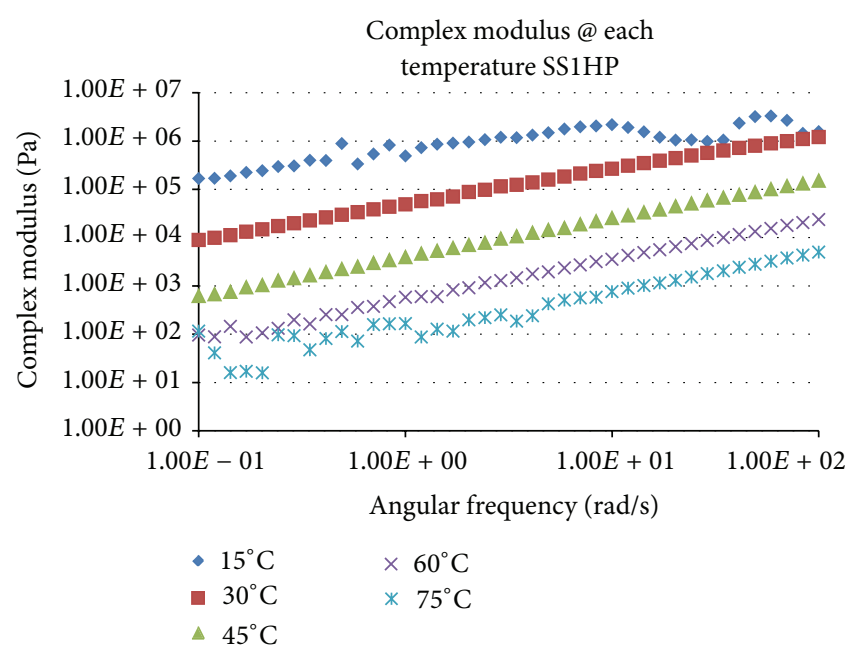

(d)

Figure 10: (a) Complex modulus, (b) complex compliance master curves, (c) phase angle at $45^{\circ} \mathrm{C}$, and (d) complex modulus at each temperature.

measurement temperature, $T_{0}$ is reference temperature, and $a_{T}$ is time-based shift factor.

\section{Analysis of Test Results}

Several trial tests are performed on the sealant samples. Based on these tests the testing frequency is selected to cover a range from $0.1 \mathrm{rad} / \mathrm{sec}$ to $100 \mathrm{rad} / \mathrm{sec}$ to cover both high and low loading speeds. The applied strain is changed to $0.1 \%$ to make sure that the sample does not damage at either low temperature or high frequency. Because of the testing time and instrument limitation, the temperature range also shortened from $15^{\circ} \mathrm{C}$ to $75^{\circ} \mathrm{C}$.

Totally 40 points are measured during each test. For some of the samples, it was hard to capture data at low temperature because of brittleness of the samples which may lead to damage or at high temperature because the sample was so soft to bear a shear load.

Figure 4 shows complex modulus master curve and phase angle result for each material. As shown in Figure 4(a), trackless emulsion is stiffer than other materials on the whole, but it is too brittle at high frequency or low temperature, and thus scattered results were obtained. Considering the reasons for this phenomenon, the property of trackless emulsion at these conditions is close to solid phase so that some damage might happen. In addition, the loss of contact surface between material and parallel plate can be another factor. Most commonly used emulsion, SS1HP, as a tack coat material is stiffer than HFE90. Also, it is stiffer than PG 64-22 binder at low frequency and high temperature, but if the condition of frequency and temperature are changed inversely, PG 64-22 binder is stiffer than SS1HP. Figure 4(b) shows phase angle results for each material. The result of phase angle for the trackless emulsion shows that the inflection point appears at a lower frequency, as compared with that of other materials.

As shown in Figure 5, trackless emulsion at low temperature shows lower shear strength than SS1HP for mixture of both $4.75 \mathrm{~mm}$ and $9.5 \mathrm{~mm}$. However, the opposite pattern is shown at the temperature of more than $5^{\circ} \mathrm{C}$.

4.1. Asphalt Binder PG 64-22. For PG 64-22 binder, it can be seen that the complex modulus increases as the frequency increases or temperature decreases. For the complex compliance, the behavior is inversed. In other words, it decreases as 


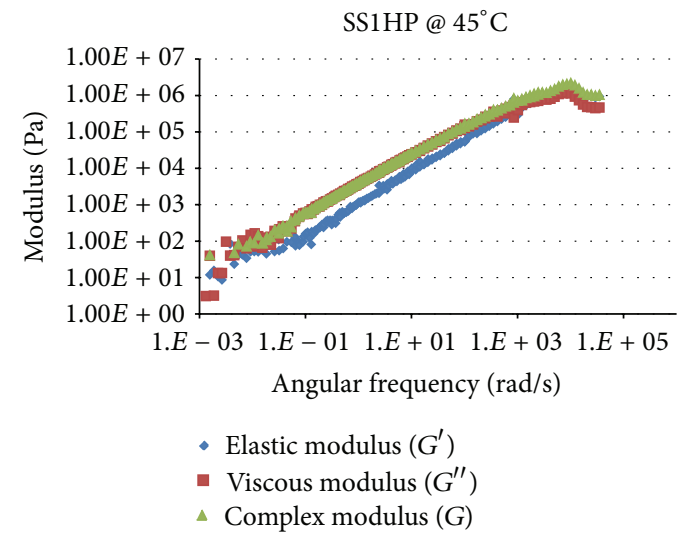

(a)

\begin{tabular}{|c|c|c|}
\hline \multicolumn{3}{|c|}{ Shift factors for SS1HP } \\
\hline $\begin{array}{c}\text { Temperature } \\
\left({ }^{\circ} \mathrm{C}\right)\end{array}$ & \multicolumn{2}{|c|}{$\log a_{T}$} \\
\hline 15 & \multicolumn{2}{|c|}{6.926} \\
\hline 30 & \multicolumn{2}{|c|}{3.203} \\
\hline 45 & \multicolumn{2}{|c|}{0} \\
\hline 60 & \multirow{2}{*}{\multicolumn{2}{|c|}{$\begin{array}{l}-2.404 \\
-4.332\end{array}$}} \\
\hline 75 & & \\
\hline \multirow[b]{2}{*}{ WLF } & $\mathrm{C} 1$ & $\mathrm{C} 2$ \\
\hline & 23.143 & 129.43 \\
\hline Arrhenius & \multicolumn{2}{|c|}{$\begin{array}{c}\text { B1 } \\
47303\end{array}$} \\
\hline
\end{tabular}

Figure 11: (a) Elastic and viscous modulus at $45^{\circ} \mathrm{C}$ and (b) shift factors at reference temperature $\left(45^{\circ} \mathrm{C}\right)$. frequency increases or temperature decreases. The maximum complex modulus obtained for this material was 4,318,000 Pa. Regarding the phase angle, it starts decreasing at a higher rate when the reduced frequency reaches an approximate value of $3,000 \mathrm{rad} / \mathrm{s}$. It occurs at $2.9 \mathrm{rad} / \mathrm{s}$ and $15^{\circ} \mathrm{C}$ for the real frequency.

Similarly, it can be noticed from the shear modulus chart that at low frequencies or high temperatures the material presents a viscous-like behavior since the viscous modules $\left(G^{\prime \prime}\right)$ are higher than the elastic modulus $\left(G^{\prime}\right)$. However, after the crossover point, where $G^{\prime}=G^{\prime \prime}$, the material changes to an elastic behavior. Here, the temperature has reduced and frequency has increased. In addition, it is important to notice that the crossover point $\left(G^{\prime}=G^{\prime \prime}\right)$ occurs when the phase angle is $45^{\circ}$ (degree). At this same point the frequency is approximately 3,000 $\mathrm{rad} / \mathrm{s}$ which is the same point discussed above where the phase angle starts to decrease at higher rate.

Considering the prediction of rutting resistance, it is necessary to know the locations where $G^{\prime \prime}>G^{\prime}$ and $G^{\prime \prime}<G^{\prime}$, since these two zones dictate the recoverable and nonrecoverable deformations. Additionally, fatigue cracking can be estimated by analyzing the complex modulus and phase angle for long-term aged materials.

Figure 6 also shows how the shear modulus is higher at low temperatures. Also, for each temperature, the modulus increases as frequency increases. Finally, Figure 7 illustrates the shift factors at each temperature at which the material was tested. The William-Landel-Ferry (WLF) coefficients as well as the Arrhenius coefficient are presented. However, Arrhenius coefficient is not suitable for this case since the temperatures used are above the glassy transition temperature $(\mathrm{Tg})$.

4.2. HFE90 Emulsion. For HFE90 emulsion, the complex modulus increases as the frequency increases or temperature decreases as can be seen in Figure 8. This behavior is common for viscoelastic materials as presented previously for the PG 64-22 asphalt binder. The maximum complex modulus obtained for this material was 3,131,000 Pa. In Figure 9, the phase angle starts decreasing at a higher rate when the reduced frequency reaches an approximate value of $4,000 \mathrm{rad} / \mathrm{s}$. The crossover point $\left(G^{\prime}=G^{\prime \prime}\right)$ occurs at this same frequency where the phase angle approximates $45^{\circ} \mathrm{C}$. It occurs at $4.9 \mathrm{rad} / \mathrm{s}$ and $15^{\circ} \mathrm{C}$ for the real frequency.

For this material, it can be seen again that for each temperature the modulus increases as temperature decreases and frequency increases. The shift factors for each temperature as well as the WLF coefficients and Arrhenius coefficient are also shown.

4.3. SS1HP Emulsion. For SS1-HP emulsion as for the two previous materials, the complex modulus increases as the frequency increases or temperature decreases as can be seen in Figure 10. The maximum complex modulus obtained for this material was $3,281,000 \mathrm{~Pa}$. In Figure 11, the phase angle starts decreasing at a higher rate when the reduced frequency 


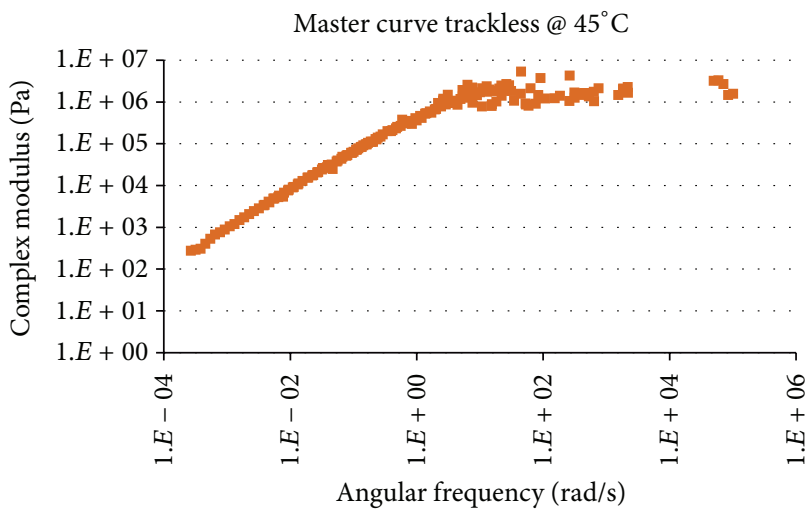

(a)

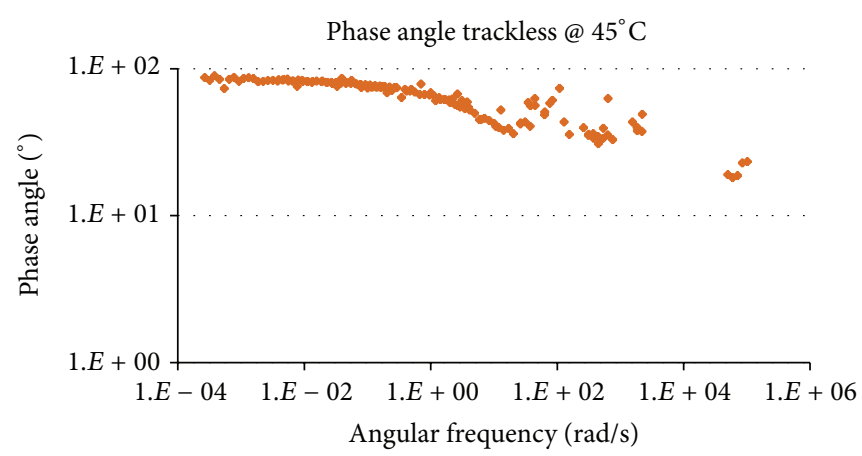

(c)

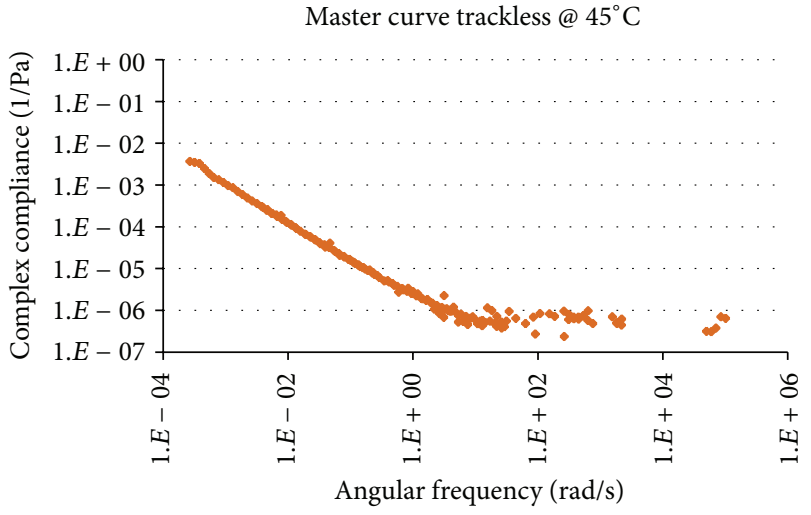

(b)

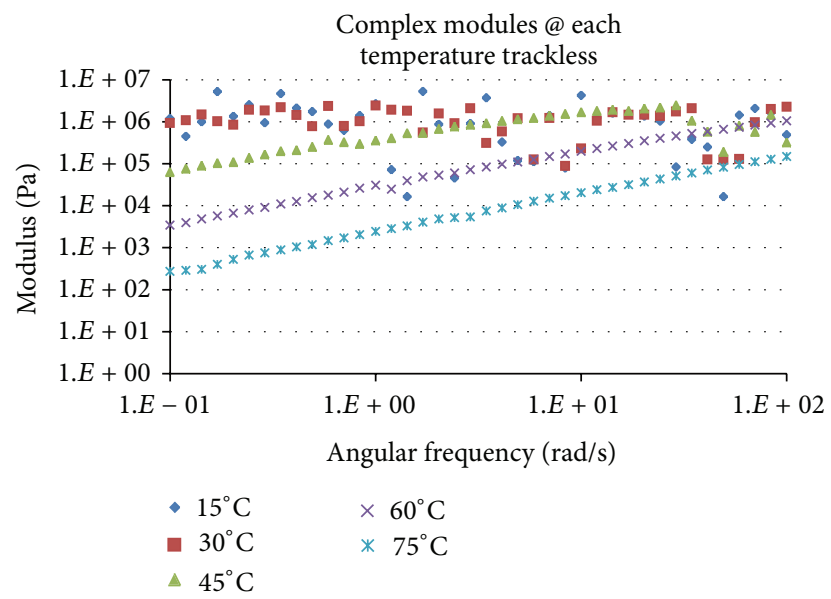

(d)

Figure 12: (a) Complex modulus, (b) complex compliance master curves, (c) phase angle at $45^{\circ} \mathrm{C}$, and (d) complex modulus at each temperature.

reaches an approximate value of $2,100 \mathrm{rad} / \mathrm{s}$. The crossover point $\left(G^{\prime}=G^{\prime \prime}\right)$ occurs at this same frequency where the phase angle approximates $45^{\circ} \mathrm{C}$. It occurs at $2.0 \mathrm{rad} / \mathrm{s}$ and $15^{\circ} \mathrm{C}$ for the real frequency.

For this material, it can be seen again that for each temperature the modulus increases as temperature decreases and frequency increases. The shift factors for each temperature as well as the WLF coefficients and Arrhenius coefficient are also shown.

4.4. Trackless Emulsion. For trackless emulsion as for the three previous materials, the complex modulus increases as the frequency increases or temperature decreases as can be seen in Figure 12. However, it became stiffer and is started to show a brittle behavior at low temperatures and high frequencies. As it becomes solid-like, it loses contact with the parallel plates during test causing difficulties to obtain a good data. In Figure 13, it can be seen that the data is scattered at high frequencies. The maximum complex modulus obtained for this material was 5,326,000 Pa. From the data obtained for this material, it is hard to predict at what frequency the phase angle starts decreasing at a higher rate. However, it was estimated to happen at a frequency less than $100 \mathrm{rad} / \mathrm{s}$.
It occurs at $2.9 \mathrm{rad} / \mathrm{s}$ and $30^{\circ} \mathrm{C}$ for the real frequency. The crossover point $\left(G^{\prime}=G^{\prime \prime}\right)$ was also estimated to happen at this same point with phase angle close to $45^{\circ} \mathrm{C}$.

Additionally, it can be seen in Figure 13 that the result of shear modulus at $15^{\circ} \mathrm{C}$ and $30^{\circ} \mathrm{C}$ behaves in an odd manner. However, as temperature increases, the data starts to stabilize. Regarding the shift factors, it can be seen that the WLF coefficients and Arrhenius coefficient are not similar to the other three materials.

4.5. Comparison of Viscous Modulus. After the results for all the material were shown, it is important to compare at what frequency the crossover point takes place for each material. It was found that for the HFE90 emulsion the crossover point occurred approximately at 4,000 rad/s, which means that for this product the transition from viscous to elastic behavior takes place at lower temperatures comparing to the other three materials. On the other hand, it can be seen from Figure 14 that HFE90 has one of the lowest viscous shear moduli.

Conversely, crossover point of the trackless emulsion was estimated to happen at less than $100 \mathrm{rad} / \mathrm{s}$, which means that this material will become elastic at intermediate 


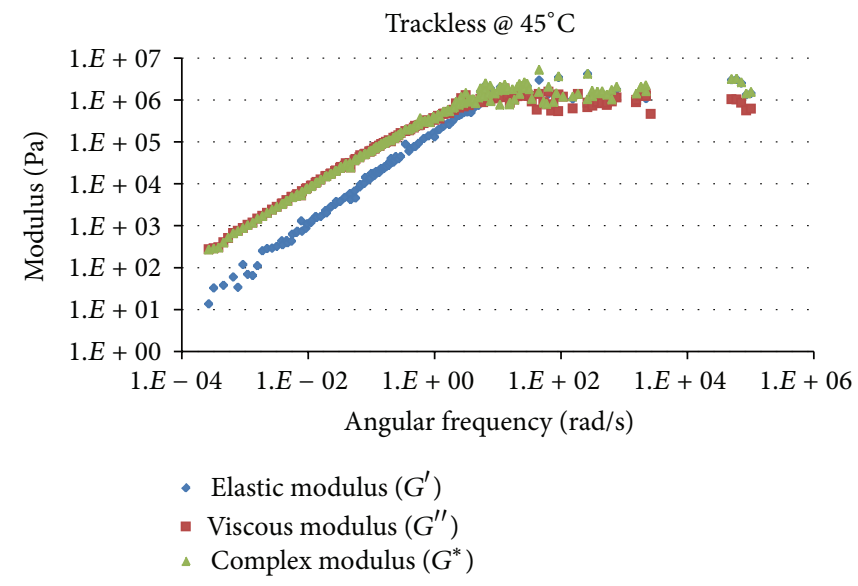

(a)

\begin{tabular}{|c|c|c|}
\hline \multicolumn{3}{|c|}{ Shift factors for trackless emulsion } \\
\hline $\begin{array}{c}\text { Temperature } \\
\left({ }^{\circ} \mathrm{C}\right)\end{array}$ & \multicolumn{2}{|c|}{$\log a_{T}$} \\
\hline 15 & \multicolumn{2}{|c|}{3.276} \\
\hline 30 & \multicolumn{2}{|c|}{3.089} \\
\hline 45 & \multicolumn{2}{|c|}{0} \\
\hline 60 & \multirow{2}{*}{\multicolumn{2}{|c|}{$\begin{array}{l}-3.232 \\
-5.923\end{array}$}} \\
\hline 75 & & \\
\hline \multirow{2}{*}{ WLF } & $\mathrm{C} 1$ & $\mathrm{C} 2$ \\
\hline & -19.31 & 123.32 \\
\hline Arrhenius & \multicolumn{2}{|c|}{$\begin{array}{c}\text { B1 } \\
-37917\end{array}$} \\
\hline
\end{tabular}

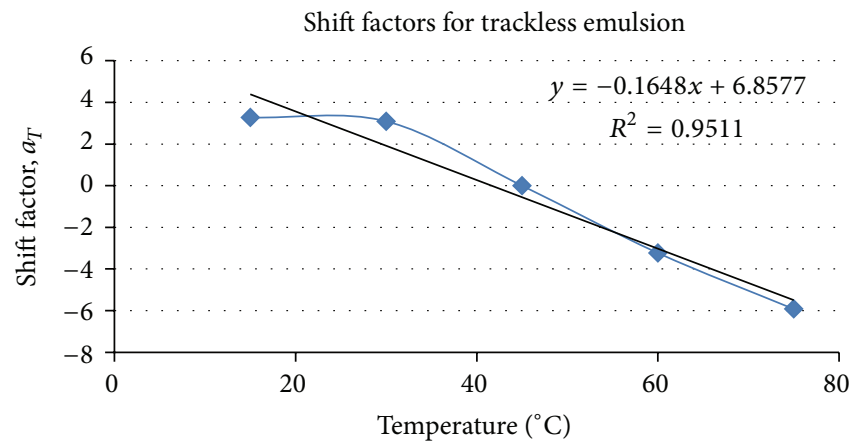

(b)

Figure 13: (a) Elastic and viscous modulus at $45^{\circ} \mathrm{C}$ and (b) shift factors at reference temperature $\left(45^{\circ} \mathrm{C}\right)$.

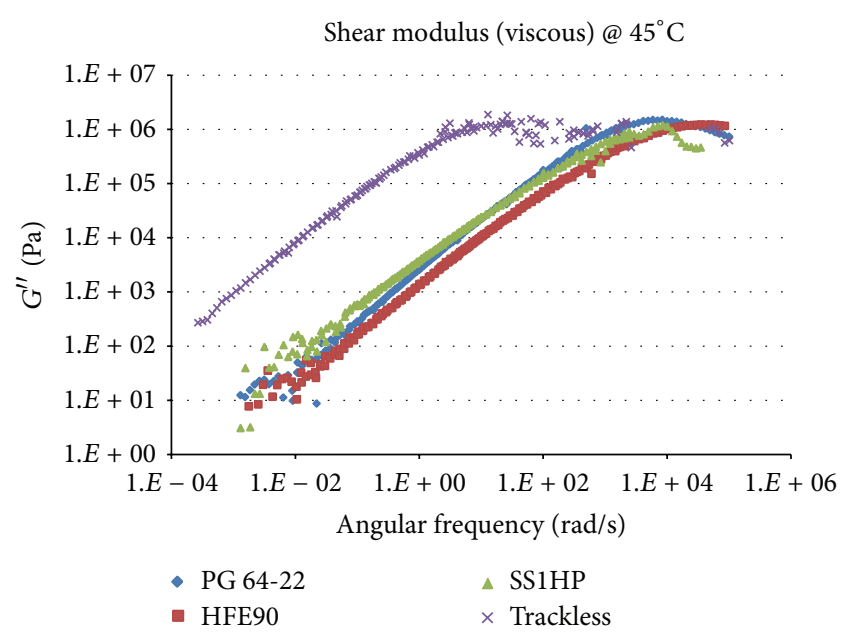

FIGURE 14: Viscous modulus for each material at $45^{\circ} \mathrm{C}$.

temperatures. Also, this product has the highest viscous modulus compared to the other three materials.

4.6. Stiffness Ratio (SR). Stiffness ratio (SR) is used to have a better comparison between different emulsions. This stiffness ratio is the modulus $\left(G^{*}, G^{\prime}\right.$, or $\left.G^{\prime \prime}\right)$ of an emulsion divided by the modulus of SS1HP product at a certain frequency and temperature:

$$
\mathrm{SR}=\frac{\text { Emulsion Modules }}{\text { SS1HP Modules }} .
$$

The SR results for viscous modulus are presented in Figure 15 at low $(0.1 \mathrm{rad} / \mathrm{sec})$, intermediate (1 and $10 \mathrm{rad} / \mathrm{sec})$, and high $(100 \mathrm{rad} / \mathrm{s})$ frequencies. Viscous modulus is an important parameter for emulsions used as a tack coat material. Having a high viscous modulus, tack coat material can perform better at high deformations between the pavement layers and provide proper and long-lasting bonding between them.

Figure 15 shows that SR depends on both temperature and loading frequency. At low frequencies, trackless emulsion has the highest modulus. At high frequencies below a certain temperature trackless emulsion turns to show the lowest modulus. We can call this point turning point for trackless emulsion product behavior. This turning point temperature depends on the frequency. As the frequency increases, the higher temperature will be obtained for the turning point. For example, at $10 \mathrm{rad} / \mathrm{sec}$ the turning point temperature is $30^{\circ} \mathrm{C}$ and at $100 \mathrm{rad} / \mathrm{sec}$ it is $20^{\circ} \mathrm{C}$.

The results from the shear testing on tack coat also show a similar behavior. For a certain shearing speed at low 


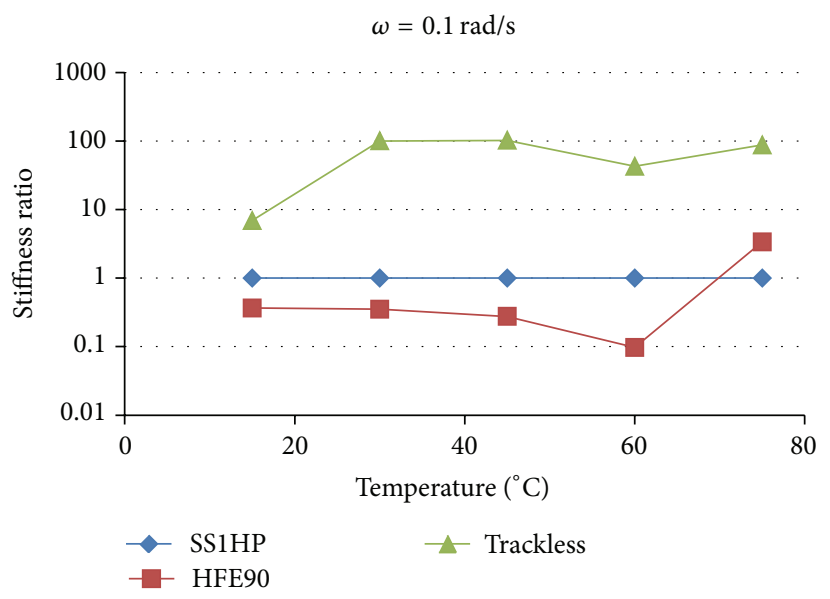

(a)

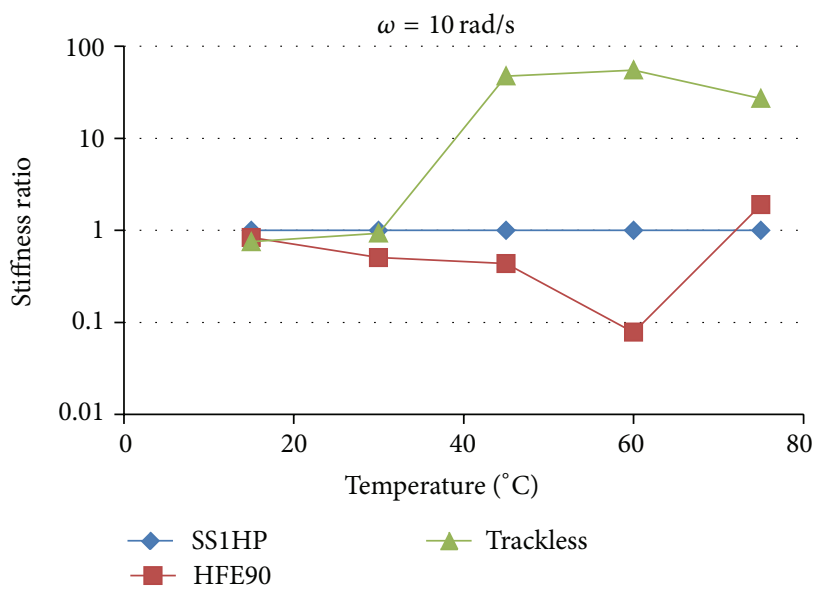

(c)

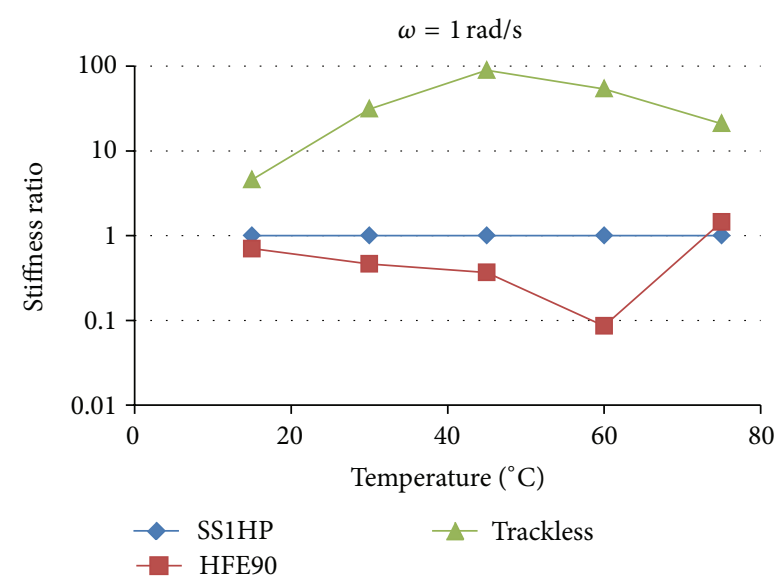

(b)

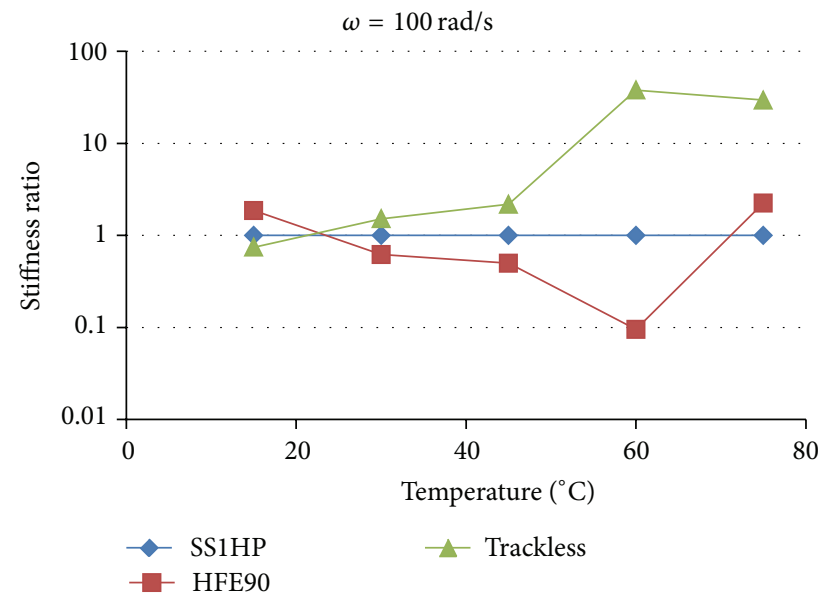

(d)

FIGURE 15: SR based on viscous modulus at different frequencies: (a) 0.1, (b) 1, (c) 10, and (d) $100 \mathrm{rad} / \mathrm{sec}$.

temperatures, trackless emulsion has lower shear strength than SS1HP product and at high temperature tack coat has higher shear strength than SSIHP.

\section{Conclusion}

In this study three different emulsion residues, such as SS1HP, HFE90, and SS-1VH (trackless), and a base asphalt binder (PG 64-22) were compared to characterize rheological properties by using DSR test. In order to capture the emulsion properties, different frequencies and temperatures were applied. Then, a master curve for shear modulus was plotted for each emulsion. The results of this study are as follows.

(i) The HFE90 emulsion presents the crossover point $\left(G^{\prime}=G^{\prime \prime}\right)$ at the highest frequency. Therefore, the transition from viscous to elastic behavior occurs at lower temperatures, compared to the other materials. This emulsion is known for performing in a wider temperature range as shown in the results.

(ii) The trackless emulsion has the crossover point at reduced frequency lower than $100 \mathrm{rad} / \mathrm{s}$. It indicates that the material presents an elastic behavior at intermediate temperatures. This product is known as having very fast setting and high resistance to shear stresses.

(iii) The trackless emulsion presents the highest viscous and elastic modulus, followed by the PG 64-22 binder, SS1HP, and HFE90 emulsion.

(iv) At high temperatures trackless emulsion has the highest modulus.

(v) Depending on the frequency below a certain temperature, trackless material has the lowest modulus. This temperature gets lower as the frequency decreases.

(vi) Shear strength test results show a behavior between trackless emulsion and SS1HP similar to the frequency sweep test results performed by DSR.

\section{Conflict of Interests}

The authors declare that there is no conflict of interests regarding the publication of this paper. 


\section{Acknowledgment}

The authors would like to acknowledge the financial support from the Korea Institute of Civil Engineering and Building Technology (KICT) under research project "Support for Commercialization of Warm Mix Asphalt."

\section{References}

[1] K. Takamura, "Comparison of emulsion residues recovered by forced airflow and RTFO drying," in Proceedings of the ISSA/AEMA Annual Meeting, pp. 1-17, March 2000.

[2] G. N. King, D. Lesueur, H. King, and J. Planche, SHRP Test Evaluation of High Float and Polymer Modified Bitumen Emulsion Residues, Koch Materials Laboratory, Terre Haute, Ind, USA, 1996.

[3] R. Barcena, A. Epps, and D. Hazlett, "A performance-graded binder specification for surface treatments," in Proceedings of the 81st Annual Meeting of the Transportation Research Board, Washington, DC, USA, 2002.

[4] C. Deneuvillers and J. Samanos, "Contribution to the study of the relationship between characteristics and performances of bitumen emulsions," in Proceedings of the 2nd Eurasphalt \& Eurobitume Congress, Book 1, pp. 195-202, Barcelona, Spain, 2000.

[5] S. Le Bec, M. Mazé, B. Brúlé, and J. Lefébvre, "Formulation of cold mixes: accelerated curing in the laboratory," in Proceedings of the 2nd Eurasphalt \& Eurobitume Congress, Book 1, pp. 416423, Barcelona, Spain, 2000.

[6] M. O. Marasteanu and T. R. Clyne, "Rheological characterization of asphalt emulsions residues," Journal of Materials in Civil Engineering, vol. 18, no. 3, pp. 398-407, 2006.

[7] ASTM D7175, Standard Test Method for Determining the Rheological Properties of Asphalt Binder Using a Dynamic Shear Rheometer, Annual Book of ASTM Standards, ASTM International, West Conshohocken, Pa, USA, 2005.

[8] D. Salomon and H. Zhai, "Rheological measurements of asphalt road emulsions," in Proceedings of the 3rd World Congress on Emulsions, Lyon, France, September 2002.

[9] H. Zhai, D. Salomon, and E. Milliron, Using Rheological Properties to Evaluate Storage Stability and Setting Behaviors of Emulsified Asphalts, Idaho Asphalt Supply, Inc., White Paper, Idaho, USA, 2006.

[10] L. Roderic, Viscoelastic Materials, Cambridge University Press, New York, NY, USA, 2009. 


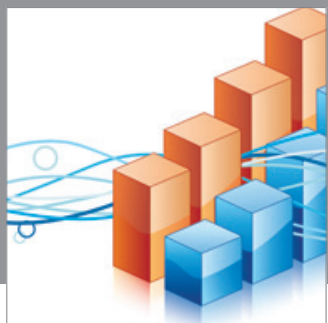

Advances in

Operations Research

mansans

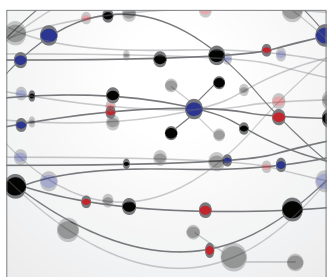

The Scientific World Journal
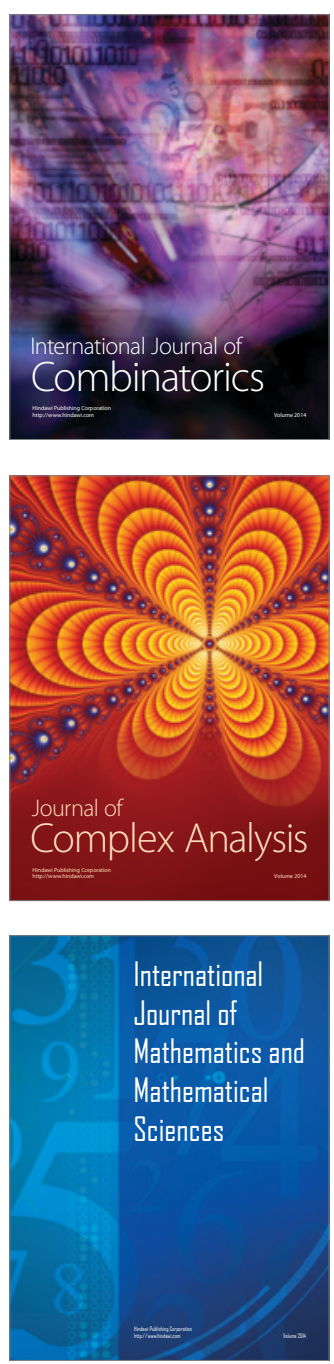
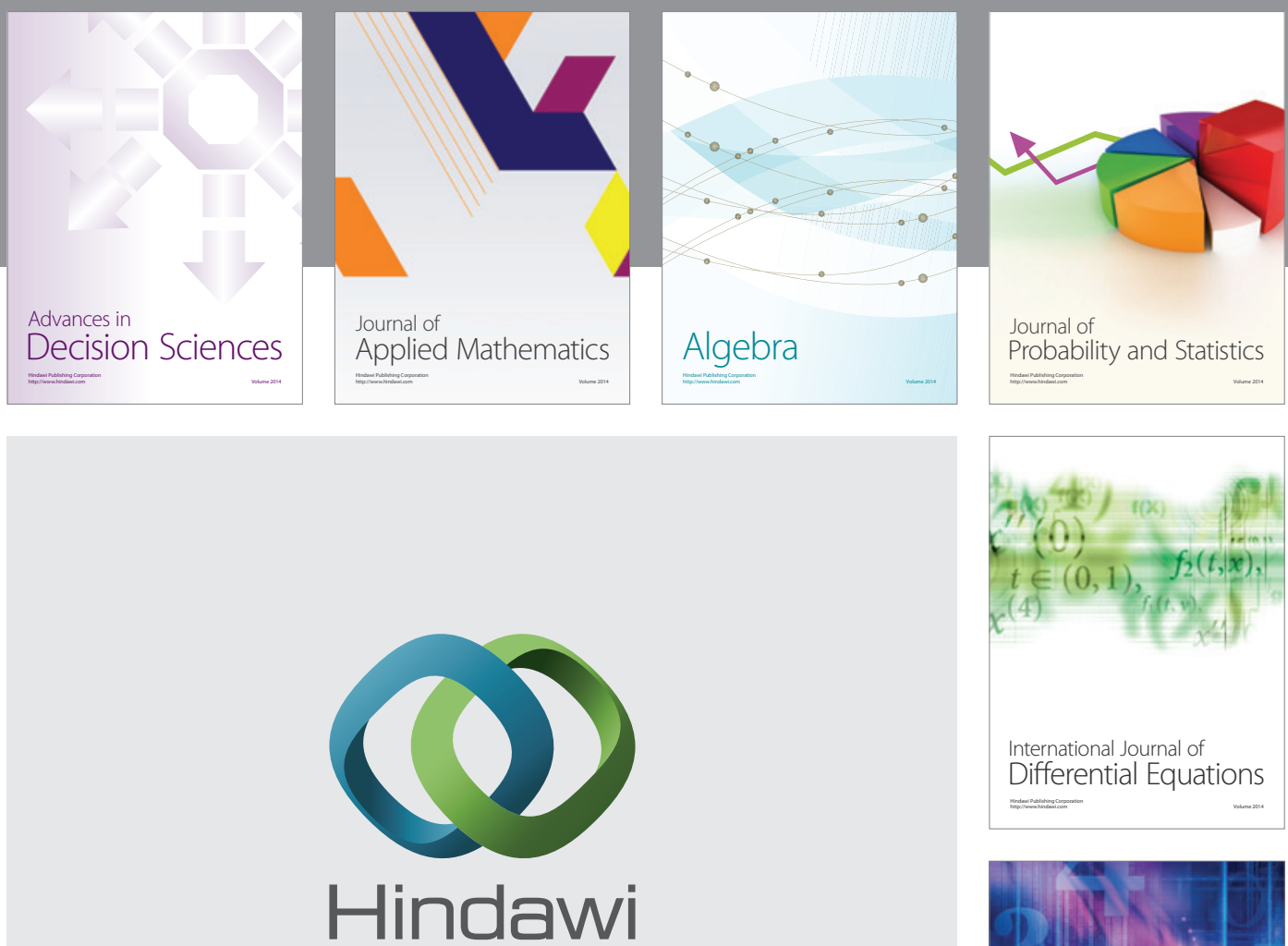

Submit your manuscripts at http://www.hindawi.com
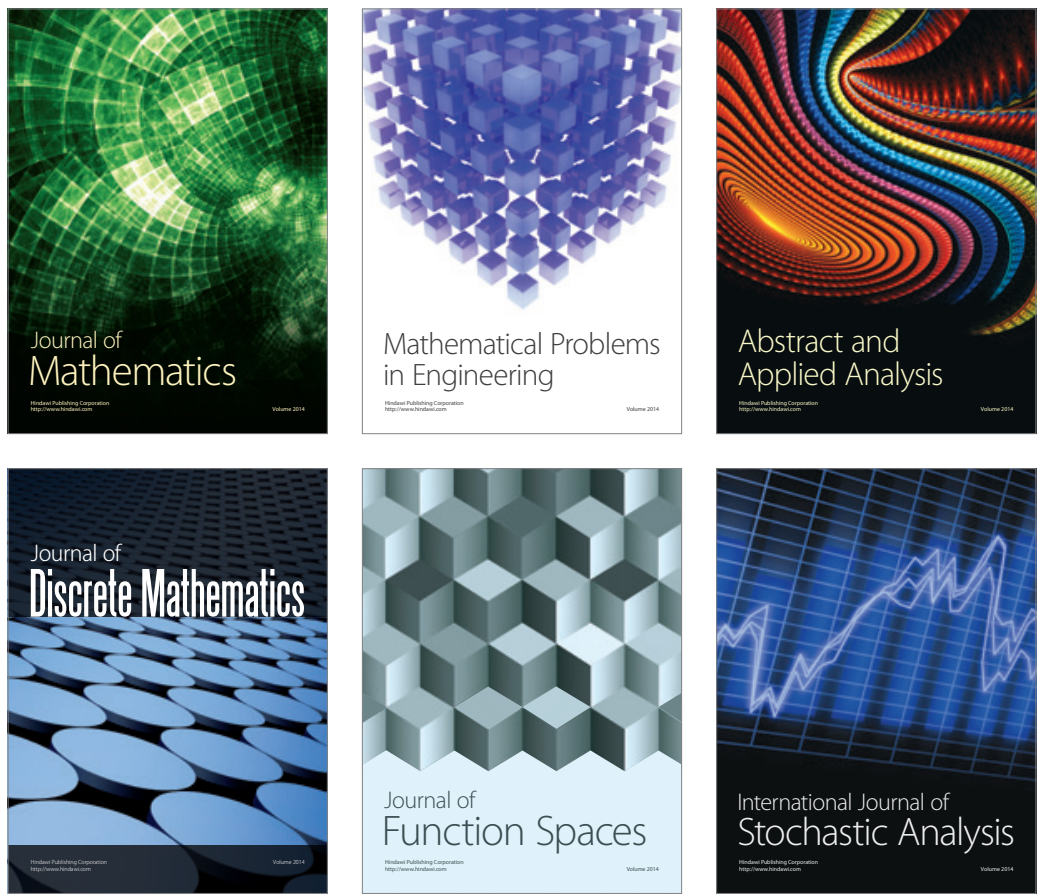

Journal of

Function Spaces

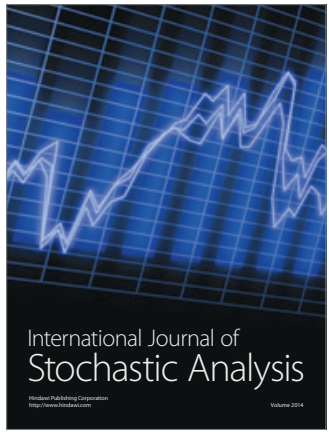

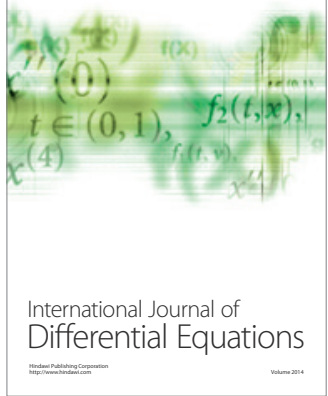
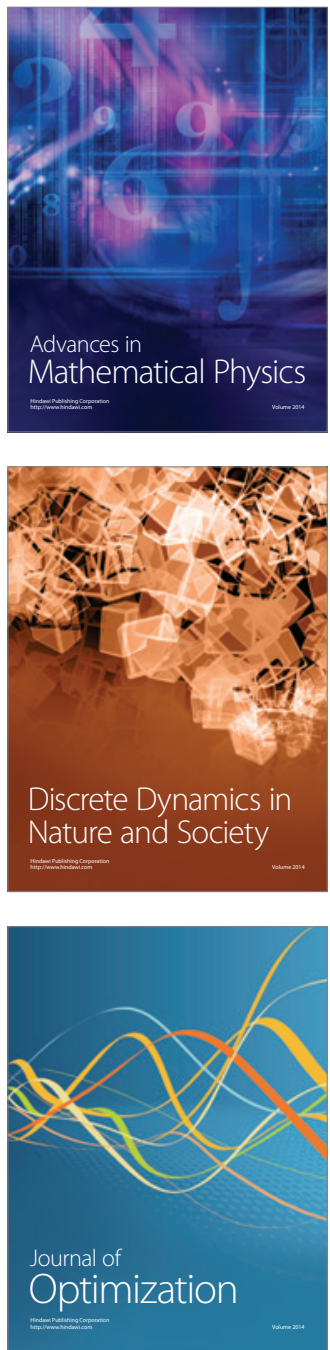